\title{
Are emergency department junior doctors becoming less experienced in performing common practical procedures?
}

\section{Susan J Croft, Suzanne Mason}

Emerg Med J 2007;24:657-658. doi: 10.1136/emj.2006.045302

A questionnaire was designed to measure junior doctors' experience of performing practical procedures and was distributed to all junior doctors working in our emergency department during June 2005 and June 2006. The junior doctors were subjectively less experienced in all the procedures measured in 2006 compared to 2005 . There were statistically significant reductions in experience of shoulder manipulation, suturing and wound exploration. Junior doctors are becoming less experienced in performing some practical procedures.

n recent years, in particular with the introduction of the foundation programme in August 2005, the role of the junior doctor in the emergency department has changed. Many within the specialty consider that junior doctors taking up emergency medicine appointments have become less experienced, are less ready to take on responsibility and are less able to make decisions. They also require more supervision and take longer to learn to usefully fulfil their service commitment. ${ }^{1}$ There are reports of similar experiences in other specialities. ${ }^{2}$

Junior doctors working in emergency departments in the UK have always had an important role in providing emergency care and are commonly required to perform practical procedures such as wound suturing and reduction of dislocated joints. In Sheffield, we wanted to identify our junior doctors' perceived experience of these procedures and also to evaluate if this was changing with time.

This study was designed to measure junior doctors' experience of performing common practical procedures at two time points: June 2005 and June 2006.

The study was based in the emergency department of the Northern General Hospital, Sheffield, an adult-only department seeing approximately 90000 patients per year. There were no changes in the way that patients with minor injuries were processed within the department during the study period. Regarding staffing, there were no changes in the number of consultants or middle grade staff working in the department, but there were an additional four senior house officers (or F2 doctors) working in the department in June 2006 compared to June 2005. There are currently seven consultants, 11 middle grade doctors, 24 doctors working at senior house officer level and one pre-registration house officer.

\section{METHOD}

A questionnaire was designed to assess junior doctors' experience of performing common practical procedures. Six procedures commonly performed in the emergency department were selected following discussion with the emergency department consultants as follows:

- Colles fracture manipulation

- Dislocated shoulder manipulation

- Suturing wounds
- Exploring wounds

- Abscess drainage

- Chest drain insertion

A 10-cm visual analogue scale (VAS) was devised to measure the doctor's experience in performing the practical procedures listed above. There were four descriptive anchor points on the line:

- No experience (0 mm)

- Some experience with support (33 mm)

- Good experience (66 mm)

- Confident alone (100 mm)

A VAS was used rather than a Likert scale as it allows expression of a subjective opinion that ranges across a continuum.

The questionnaire was distributed to junior doctors working in the department in June 2005 and again in June 2006 to be completed anonymously. The data were collected 1 year apart to ensure no seasonal variation. So that the groups compared had similar characteristics, only doctors who had been working in the department for 4 months at the time of questioning were included.

\section{RESULTS}

Of the doctors who had been working in the department for 4 months, $14(82 \%)$ responded in June 2005 and 16 (94\%) in June 2006. The mean periods since qualification were 2.32 (SD 0.82 ) and 2.39 (SD 0.80) years, respectively.

A perceived reduction in experience was noted for all listed procedures between the junior doctors in 2005 and those in 2006 (fig 1). The decrease in experience of performing shoulder manipulation, suturing and exploring wounds was statistically significant.

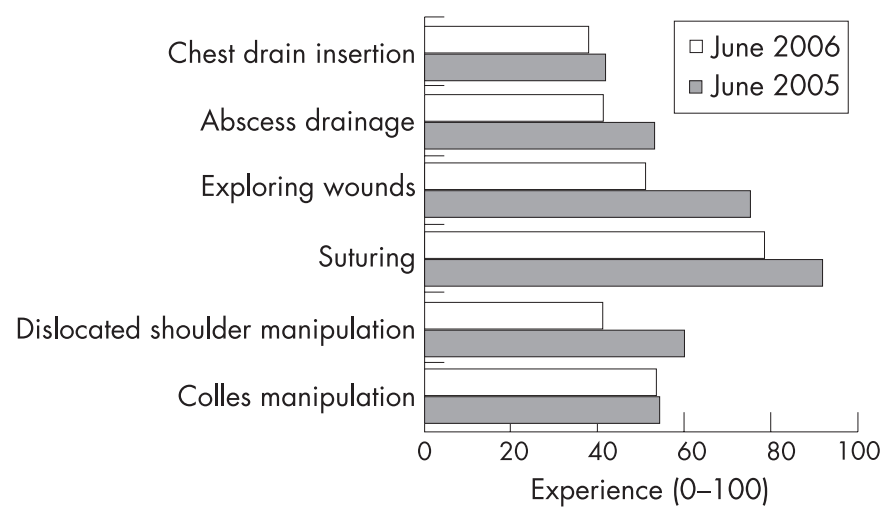

Figure 1 Junior doctors' experience of performing practical procedures. 
Table 1 Statistical analysis of the data using the unpaired $t$ test

\begin{tabular}{llllll}
\hline Procedure & $\begin{array}{l}\text { Mean } \\
\text { difference }\end{array}$ & $\mathbf{t}$ & df & $\begin{array}{l}\text { 2-tailed } \\
\text { significance }\end{array}$ & $\mathbf{9 5 \%} \mathbf{C l}$ \\
\hline Colles fracture manipulation & 0.35 & 0.04 & 27.8 & 0.97 & -19.10 to +18.40 \\
Shoulder manipulation & 18.60 & 2.20 & 27.6 & 0.04 & -35.92 to -1.28 \\
Suturing wounds & 14.51 & 2.34 & 16.2 & 0.03 & -27.44 to -1.58 \\
Exploring wounds & 24.06 & 2.43 & 27.1 & 0.02 & -44.33 to -3.79 \\
Abscess drainage & 11.5 & 0.92 & 27.5 & 0.36 & -37.03 to +14.03 \\
Chest drain insertion & 4.20 & 0.43 & 27.3 & 0.67 & -24.36 to +15.96 \\
\hline Cl, confidence interval. & & & & &
\end{tabular}

\section{Limitations}

This is a small, single centre study looking at junior doctors' experience. Both groups of doctors had been working in the department for 4 months and had been qualified for a similar length of time. However, every group of doctors varies in experience and confidence.

\section{DISCUSSION}

We have demonstrated that in our hospital, junior doctors' perceived experience of carrying out common procedures decreased between June 2005 and June 2006. There are many reasons why this may have occurred:

1. Foundation doctors are being encouraged not to perform procedures until they have been taught thoroughly and are completely competent, rather than following the old adage of "see one, do one".

2. Foundation doctors are spending more time receiving external teaching and undergoing assessment than previously, allowing them less on-hands experience and less teaching related to their current post.

3. Due to target pressures within the department, the consultants and middle grade staff may be performing more procedures themselves so that the patient doesn't "breach" specified waiting times, rather than teaching and supervising the junior doctors.
Further work is required to identify whether this problem is widespread in UK emergency departments.

\section{CONCLUSION}

In our emergency department, junior doctors consider that their practical experience of performing procedures is decreasing. This decrease in experience needs to be addressed so that junior doctors can continue to provide an important role in emergency care.

\section{ACKNOWLEDGEMENTS}

We would like to thank the junior doctors who completed questionnaires.

\section{Authors' affiliations}

Susan J Croft, Northern General Hospital, Sheffield, UK Suzanne Mason, Medicine, Northern General Hospital, Sheffield, UK Competing interests: None declared.

Correspondence to: Susan J Croft, Northern General Hospital, Herries Road, Sheffield S5 7AU, UK; susancroft@btinternet.com

Accepted 8 June 2007

\section{REFERENCES}

1 Reid C. ASME proposals for reform of SHO training: threat or opportunity for the speciality of accident and emergency. Emerg Med J 2002;19:231-3.

2 Laing CM. Firm foundation for senior house officers (letter). BMJ 2004;329:230. 